\title{
Increasing the laying depth of the foundations fordeepened underground buildingsparts
}

\author{
Anatoly Goncharov*, and Vladimir Yefimov \\ Moscow State University of Civil Engineering, 129337, Moscow, Russia,
}

\begin{abstract}
The article lays down the basic rules for increasing the laying depth of foundations and gives examples of how these works are carried out if the underground part of the building needs to be deepened. With the small size of the deepening of the basement in low-rise buildings, it is possible to deepen the foundations without hanging them at a lower cost. Meanwhile the risk of uneven sedimentary deformations is lower than whilehanging of load-bearing walls with the device of through beams. If it is necessary to deepen the underground part with an increase in the bearing capacity of the foundations, it is most rational to use composite piles which are submerged with pressure and are supported by existing belt foundations. The application of this method requires the mandatory installation of distributing beams under the tape foundation,providing the transfer of the load from the pile indentation on the volume of the structures,significantly exceeding by the weight of the indentation force.
\end{abstract}

\section{Introduction}

A distinctive feature of modern urban construction is the desire to significantly increase the volume of the underground part of buildings [1-3]. This is especially true when performing construction work in the central part of large cities. This is explained not only by the severe need to remove personal vehicles from the streets of city residents, but also by the attractiveness for investors of placing additional facilities in areas with developed infrastructure. The development of underground space in some cases simplifies the preservation of the historical buildings of cities.

In the underground part of the reconstructed buildings, in addition to parking lots, there are also vehicle service stations, warehouse premises for shops, refrigerators, restaurants and cafes, cinemas, civil defense facilities and, of course, engineering communications.

When reconstructing industrial buildings in the underground part, it is sometimes more profitable (safer) to locate some technological processes.

\section{Materials and Methods}

\footnotetext{
*Corresponding author:efimov1234@mail.ru, ttg38@mail.ru
} 
Geometrical parameters of the reconstructed underground part are determined by its purpose. Reconstruction methods are determined by the features of the surrounding buildings, soil conditions and many other factors [3-5]. Modern construction technologies for the production of "zero cycle" works make it possible to solve any engineering problems [6, 7] but at the same time, these works are the most expensive and responsible. More than $70 \%$ of construction accidents occur due to errors at the stage of geotechnical works. Therefore, the choice of the dimensions and structural scheme of the underground part, the choice of the technology for its reconstruction are a responsible task in the design; they require a technical and economic comparison of various options, taking into account the entire complex of geotechnical problems.

When reconstructing the underground part, as a rule, it becomes necessary to deepen the foundations. When performing this operation, it is obligatory to hang the load-bearing walls with the help of beams passing through the holes in the walls (Fig. 1) and resting on special supports with jacks that allow to remove the resulting deformations [6]. Hanging loadbearing walls with the elimination of vertical deformations requires the installation of reliable supports with jacks and constant monitoring. In this case, the supports are located on the outer and inner sides of the building, and the deepening of the foundations is performed, as a rule, before the start of work on deepening the basement. Sometimes it is required to strengthen the walls at the places where the through beams are installed. The practice of performing these works shows that it is rarely possible to avoid sedimentary deformations that occur at different stages of the work and often lead to the appearance of cracks in the walls of the building.

When reconstructing old low-rise buildings, it is often necessary to slightly deepen the basement when deepening the soles of the strip foundation. Sometimes it is necessary to transfer the sole to the stronger layers of the base soil.

\section{Results}

The distinctive feature of modern urban construction is the intention for a significant increase in the volume of the underground part of buildings [1-3]. This is particularly true while performing construction work in the central part of large cities. This is due not only to the severe need to remove private vehicles from the streets of the city, but also to the attractiveness for investors of the location of additional facilities in areas with developed infrastructure. The development of underground space in some cases facilitates the preservation of historical urban development.

In the underground part of the reconstructed buildings besides car parkings there are also houses vehicle service stations, store rooms, refrigerators, restaurants and cafes, cinemas, civil defence facilities and, of course, engineering communications.

In the renovation of industrial buildings in the underground part, it is sometimes more profitable (safe) to accommodate certain technological processes.

The geometric parameters of the reconstructed underground part are determined by its purpose. The ways of reconstruction are determined by the features of the surrounding building, the ground conditions and many other factors [3-5]. Modern construction technologies of manufacture of works of «zero cycle» allow to solve any engineering tasks $[6,7]$; but at the same time these jobs are the most expensive and the most responsible. More than $70 \%$ of construction accidents occur for a reason of errors in the geotechnical stage. Therefore, the choice of the dimensions and design of the underground part, the choice of the technology of its reconstruction is a responsible task in the design, and it is necessary to carry out a technical and economical comparison of the various variants taking into account the whole complex of geotechnical problems. 
While reconstructing the underground part, the necessarity of foundation deepening appears. During this operation, the load-bearing walls should be hung by beams passing through openings in the walls (Figure 1) and supported by special supports with jacks to avoid any deformations arising [6]. The hanging of load-bearing walls, with the exception of vertical deformations, requires the installation of reliable jack-mounted supports and continuous monitoring. Furthermore, the supports are located from the external and internal sides of the building, and deepening of foundations is done as a rule until the beginning of work by the deepening of the basement. Sometimes wall reinforcement is required at points where through beams are installed. The practice of performing these works shows that it is rarely possible to avoid sedimentary deformations occurring at different stages of the work and often resulting in cracks in the walls of the building.

In the reconstruction of antique low-rise buildings, it is often necessary to deepen the basement slightly when deepening the bottom of tape foundation. Sometimes it is necessary to transfer the bottom to the stronger layers of the ground of the base.

The method for deepening the foundations depends on many factors: ground conditions, the size of the increase in workload the need to change the configuration of the foundation, the size of the deepening, etc. The choice of method is also determined by the technical capabilities of the construction organization performing the work.

While reconstructing of an underground part of a number of objects in Moscow, the foundations have been successfully deepened with the deepening of the floor of the basement without hanging the load-bearing walls during slight vertical deformations and the complete absence of uneven sedimentary deformations. Examples of how the work was carried out using different methods are given below.

Example 1.While the overhaul of the 3-storey brick that has been built in the late 19th century, located nearby the Trubnaya Square, it was decided by the customer to increase the height of the basement by $70 \mathrm{~cm}$ (the existing height of $180 \mathrm{~cm}$ from the floor to the ceiling).

During the survey of the foundations, it was found that the external bearing walls with a thickness of $105 \mathrm{~cm}$ didn't have broadening in the lower part and were deepened $20 \mathrm{~cm}$ from the basement floor mark (concrete floor is $10 \mathrm{~cm}$ thick). The brick of the lower rows is in working condition and corresponds to the mark M50. At the same time the lime solution of the seams with sufficient strength has practically no adhesion with the brick in the lower rows of the masonry. The soil of the base is a semi-solid-state loam. Increase of the load on the base is not expected.

By the results of produced loads collection and the determination of the operating voltage values and also taking into account the limited capabilities of the organization, there was taken a decision to deepen the basement without deepening the foundations with a reinforced concrete retaining wall with anchors (figure 1).

With the adopted basement deepening scheme, some increase in voltage in the ground of the base occurs, depending on the angle of internal friction. But taking into account the condition of the bearing walls (no damage and deformation, connected with uneven precipitation), a safe increase in the load on the base to $15-20 \%$ has been proven by practice [1].

The working fittings of the retaining wall is located from the basement side for the perception of horizontal stresses. Driven into the ground anchors, that are made from channel, prevent possible horizontal displacement of the retaining wall in the lower part. 


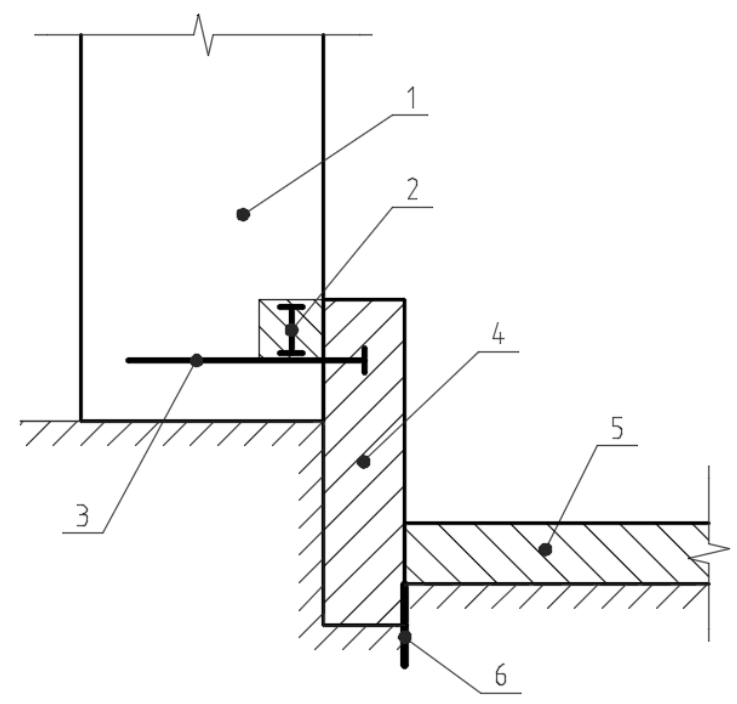

Fig. 1.Basement deepening with device of retaining wall1 - existing foundation; 2 - distribution beam; 3 - the anchor; 4 - retaining wall; 5 - monolithic plate; 6 - ground anchor.

The works were carried out in accordance with the technological map agreed with the customer.

Beforehand, the middle part of the basement rooms was excavated between the bearing walls, leaving the slopes at the walls steep not more than $40^{\circ}$. Simultaneously, there were arranged anchors out of rebar A400 Ǿ16 mm with a step of $50 \mathrm{~cm}$ along the perimeter of the walls with a deepening in the masonry for 50-60 cm. The concreting of the retaining wall was carried out by grips of 1-metre-wide. For this purpose, a special formwork (4 pieces) was made with pipe limiters enabling it to be installed in the design position for several minutes. The team of workers performing the work was given the task: from the moment of formation of a vertical wall (slope digs) on the grip with a width of $1 \mathrm{~m}$ until the end of concreting of the retaining wall on given grip (installation waterproofing, fittings, installation of formwork and concreting) should take no more than two hours. The volume of concrete is 140 liters. Preparation is made on the place. Works were carried out in one shift (12 hours). Up to four grips a day, that were located in different parts of the building, were concreted. After day, the formwork was moved to the neighboring grip with a oneway setting of the limiter.Before starting the work on the basement sinking, risks were applied from the outside of the building (at the corners) with a level reference to the control risk (on the neighboring building). Re-leveling was performed 9 months after the completion of the work. Additional residue of the building wasn't found. At the same time, the retaining walls were examined. Damage wasn't found in the area of anchor.

The described deepening method was also applied in a building with prefabricated tape foundations under the walls of blocks.

Example 2.The height of the technical basement in the 3-storey mansions of the new elite cottage village near the town of Odintsovo is $1.5 \mathrm{~m}$. The buyer of one of the houses asked to increase the height of the basement on 1,3 meters.Considering that the belt foundation is a monolithic reinforced concrete frame with a width of $0.9 \mathrm{~m}$ and a height of $600 \mathrm{~mm}$ with a reinforcement of $6 \varnothing 616 \mathrm{~A} 400$, the customer was offered two variants of deepening: the first - the device of the retaining wall with saving the depth of laying of the foundation, and the second is deepening with increasing depth of foundation on $1 \mathrm{~m}$. 
Despite the much more volume of concrete and of labor expenditures in the second option, this option was chosen by the customer, as it provides a slightly larger basement area and appears to be more reliable.Before starting of work the theodolite was used to test the verticality of the building in four corners. The deepening of the tape foundation was carried out by grips $1 \mathrm{~m}$ wide without hanging the load-bearing walls. At the same time, they performed trenching and preparation for concreting on 4 grips located on different areas, that are distant from each other. Laying of concrete on 4 prepared grips with a total volume of 4 cubic meters was performed in approximately 3 hours. Concrete mixture from mixer with volume of 4 cubic meters was taken into specially made container.

The capturing works were carried out in the following sequence:

- development of soil manually and cleaning foundation sole;

- tamping of crushed stone into the base;

- device for concrete preparation with a thickness of $50 \mathrm{~mm}$, projecting $500 \mathrm{~mm}$ inside the room;

- device for roll waterproofing by the external vertical ground wall and the concrete preparation of the base with the release inside the room;

- installation of horizontal fittings with release into the room;

- installation of formwork;

- laying of concrete mixture.

After finishing of concreting on grip, the contact of the newly laid concrete with the sole of the existing (upper) foundation was ensured. For this purpose, the upper edge of the longitudinal shield of the formwork was $3-5 \mathrm{~cm}$ above the bottom of the foundation and had a bevel to allow for the free immersion of the vibrator (fig. 2). The triangular console that was formed after concreting was cut down when the longitudinal shield of the formwork was removed after 24 hours of finishing of concreting. The shuttering shield was moved to the next position after the ground development and the sole cleaning on the next grip adjacent to the previous one.

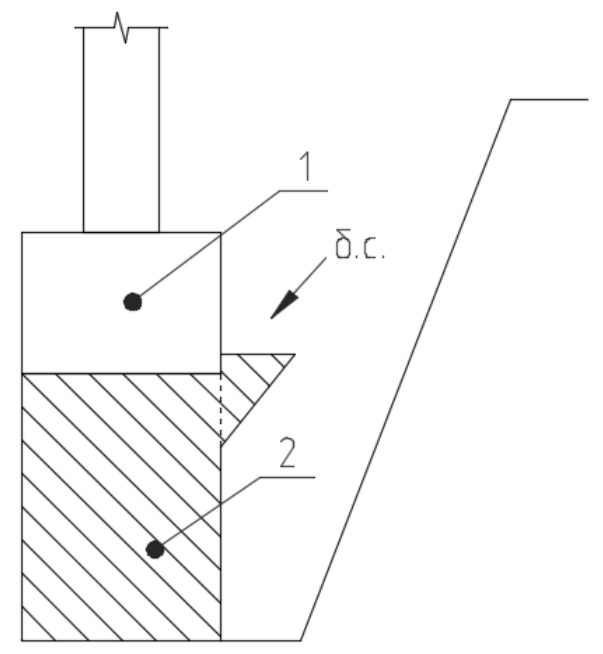

Fig. 2.Deepening of the basement1 - existing monolithic tape foundation; 2 - monolithic insert.

After the completion of the deepening foundations work in the basement room there was concrete preparation, coil waterproofing was laid and fitting was installed by connecting it to the foundation's fittings. The thickness of the plate was assumed to be 200 $\mathrm{mm}$. The full amount of work on deepening of the basement was completed within 1.5 months. Repeated measurements of vertical marks at the corners of the building has been 
executed after 1 month after the completion of the work. The sedimentary deformations by all angles were $3 \mathrm{~mm}$. There was no uneven precipitation.

Example 3. The 4-storey brick building had cracks in the bearing walls associated with uneven precipitation, with a variable crack opening during the year. While the reconstruction, it was planned to deepen the basement by a significant increase in load on the foundation. With these factors, the method of indentation of the composite piles (Mega piles) with the jacks resting on the existing belt foundations was adopted. This method was widely used to strengthen the foundations and to correct building tilt. However, after the appearance of machines that strengthen the device of drill-injection and soil-cement piles without developing large volumes of soil, this method remained effective only if it is necessary to simultaneously deepen the underground part of the building.

A fundamental scheme of penetration of pile is shown in Fig. 3.

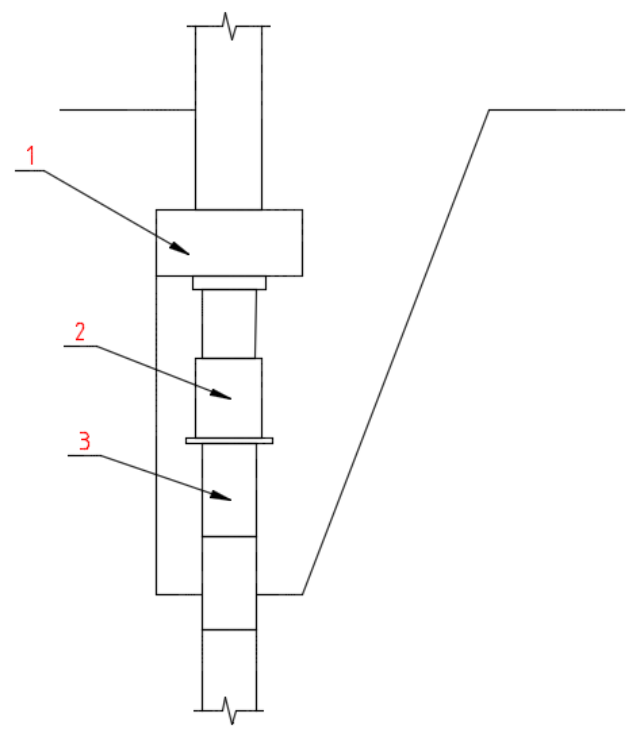

Fig.3. Scheme of sinking of composite pile by pressing-in 1 - existing belt foundation; 2 - jack; 3 link of a composite pile.

In accordance with the specification of Building Codes and Regulations 3.02.01-87, the required impressing force $\mathrm{N}$, which provides the specified load - bearing capacity of the pile $\mathrm{Fd}$, is determined from the condition $\mathrm{N} \geq 1.2 \mathrm{Fd} / \mathrm{m}$, where $\mathrm{m}$ is the coefficient of working conditions, accepted in the absence of experimental data $\mathrm{m}=0.9$. The estimated load on the base after reconstruction is 20 tons per 1 linear meter of the load bearing wall. It was decided to place the piles with a step $1.5 \mathrm{~m}$. In this case, the bearing capacity Fd of one pile must be at least $1,2 \cdot 20 \cdot 1,5=36 \mathrm{t}$, and the indentation force must be at least $1,2 \cdot 36 / 0.9=48 \mathrm{t}$. Hydraulic jacks with a force of up to $50 \mathrm{t}$ were used for indentation. As elements of a composite pile, pipe cuts $\varnothing 168 \mathrm{~mm}$ long and $60 \mathrm{~cm}$ were used, which were welded by arc welding. The lower element had a tip. Trenching to a full depth of $1.5 \mathrm{~m}$, sufficient to accommodate the Jack and the indented pipe element (taking into account the height of the distribution beam) was performed with a width of no more than $1 \mathrm{~m}$, sufficient to perform indentation work. A $3 \mathrm{~m}$ long distribution beam was installed in a slot under the foundation base for uniform load distribution with additional temporary spacers.

The accepted length of the beam provided a value of the mass of structures per jack, exceeding 60 tons, which guarantees protection during indentation. To the last indented element, in the absence of precipitation, with the maximum indentation force, two support 
posts with linings at the top were welded, touching the distribution beam. After that, the jack was removed and the pipe was filled with concrete (with pre-installation of reinforcement). While performing work on the next (through one) grip, the distribution beams were welded together. After the completion of the indentation work and the completion of the basement deepening work in about a month, the jack was re-installed on the piles and the values of the load at which it is possible to move the upper gasket were determined.

According to the results of the performed tests, it was found that the forces acting in the piles differ by no more than 1.3 tons. The values of the operating forces were equalized by installing new gaskets of the required thickness with the same (average) force on the jack.Vertical walls to the height of the basement deepening were concreted after the end of work on regulating the current loads on the piles.Geodetic control of vertical deformations was carried out during the entire period of work. Vertical deformations of the building (lifting) after completion of work were 4-6 mm. This is due to the fact that the work was performed before the planned increase in the load on the foundations. Two months after the completion of the reconstruction and commissioning of the building, a visual inspection of the external and internal walls of the building was performed. Nocracksorother damage were found.

\section{Conclusion}

The choice of the method of increasing the depth of foundations should be chosen subject to the existing loads, ground conditions and other factors of influence.

In low-rise buildings with a small level of deepening, it is advisable to perform work without hanging out the foundations.

If it is necessary to strengthen the foundations with a simultaneous increase in the depth of the underground part of the building, the most rational and reliable method that does not require a large amount of geological surveys is the method of indentation composite piles with their subsequent joints concreting on the site of deepening of the underground part.

\section{References}

1. D.S. Konyukhov, Use of Underground Space (Moscow, Architecture-C, 2004)

2. A.B. Ponomarev, Reconstruction of Underground Space (Moscow, Publishing house ACB, 2006)

3. V.A. Ilyichev, Proceedings of the anniversary conference, dedicated to RSSMGFE (Moscow, 2007)

4. I. V. Kolybin, Proceedings of the anniversary conference, dedicated to RSSMGFE (Moscow, 2007)

5. P.A. Konovalov,V.P. Konovalov, Basis and foundations of reconstructed buildings (Moscow,ACB, 2011)

6. S.O. Zege,I.I. Broyd, Proceedings of an international conference on geotechnology 4, (2010)

7. A.I. Vaingolts et al., Materials of the IX all-Russian scientific and technical conference, 385-389 (2016)

8. A. P.Krivorotov, O. A. Korobova, Proceedings of higher educational institutions. Construction and architecture 9, 121-125 (1988)

9. E. P.Vyatkina, Polzunovskiialmanac 1, 66-68 (2018) 
10. I. N. Emelyanova, Collection of articles based on the materials of the XII international scientific and practical conference, 66-73 (2018)

11. O. A.Korobova et al., Proceedings of the Novosibirsk state University of architecture and civil engineering (sibstrin) 21(4) (70), 102-111 (2018)

12. A. N.Polishchuk, Construction and architecture 2, 130-160 (2015)

13. I. E.Yazev, O. V. Petreneva, Modern technologies in construction. Theory and practice 2, 330-343 (2017)

14. T. A.Verminskaya, Almanac of modern Science and Education 7, 37-39 (2008)

15. O. Gamayunova et al., Journal of Physics: Conference Series, 1614, 012066 (2020) doi:10.1088/1742-6596/1614/1/012066 